\title{
"Um eugênico, enfim": o gaúcho como tipo antropológico na literatura e no discurso social brasileiro
}

Luciana Murari*

\section{RESUMO}

Este artigo analisa a definição da identidade social do gaúcho através de suas manifestações na literatura e no pensamento político brasileiro, a partir de textos de José de Alencar, Apolinário Porto Alegre, Euclides da Cunha, Alcides Maya, Roque Callage e, sobretudo, Oliveira Viana. Este último foi um dos mais importantes teóricos do autoritarismo brasileiro nas décadas de 1920 a 1940 e um dos maiores entusiastas do uso do argumento etnológico aplicado à sociologia brasileira. A caracterização do tipo regional do extremo sul do país, em contraste com os demais tipos humanos brasileiros e com o hispânico, foi utilizada, entre a segunda metade do século XIX e a primeira do XX, para uma afirmaçáo político-sociológica de sua superioridade e seu pretenso papel de vanguarda dos destinos nacionais. Esta ideia tem seu auge na produção sociológica de Oliveira Viana.

Palavras-chave: Pensamento político; identidade social; Rio Grande do Sul; Francisco José de Oliveira Viana.

\section{ABSTRACT}

This article analyses the gaúcho as a social identity in Brazilian literature and political thought through the works of José de Alencar, Apolinário Porto Alegre, Euclides da Cunha, Alcides Maya, Roque Callage and, mainly, Oliveira Viana. The latter was one of the most important authoritarian theorists in Brazil from the 1920s to the 1940s, enthusiastically using the ethnic argument applied to Brazilian sociology. From the second half of the nineteenth century to the first half of the twentieth, regionalist literature contrasted the typical man from the extreme South of Brazil to other Brazilian and Hispanic people in order to affirm the superiority of the gaúcho, and his supposed avant-garde role in national affairs. This idea reaches its zenith in Viana's sociology works.

Keywords: regionalist literature; political thought; social identity; Rio Grande do Sul; Francisco José de Oliveira Viana.

* Doutora em História pela Universidade de São Paulo (USP) e professora na Pontifícia Universidade Católica do Rio Grande do Sul. Porto Alegre, RS, Brasil. E-mail: lmurari@hotmail.com. 
Eu vi corpos de tropas mais numerosos, batalhas mais disputadas; mas nunca vi, em nenhuma parte, homens mais valentes, nem cavaleiros mais brilhantes do que os cavaleiros rio-grandenses, em cujas fileiras comecei a desprezar o perigo e a combater dignamente pela causa sagrada das gentes.

Fala atribuída a Giuseppe Garibaldi, citada por Oliveira Viana

\section{Tipos antropológicos regionais}

Nas últimas décadas do século XIX, a descrição do gaúcho como tipo antropológico característico do extremo-sul do Brasil já se havia estabelecido como um tema da literatura, da historiografia e dos estudos sociais, o que se observava não apenas em nível regional, mas também no contexto nacional. Definir as peculiaridades do homem sulino compreendia explicar sua gênese social, interpretar sua experiência histórica, descrever seus modos de vida, sua cultura material e sua mentalidade, determinar seu papel na construção da nação brasileira e contrastá-lo com os demais tipos regionais do país.

Neste trabalho, buscamos apresentar algumas análises e representações sociológicas e literárias do tipo social gaúcho, observando a comunicação entre literatura ficcional e o pensamento sociopolítico. Centramo-nos na obra de Oliveira Viana, um dos maiores teóricos do autoritarismo brasileiro e um dos intelectuais mais influentes de sua época. Ele dedicou ao tipo regional do extremo-sul uma obra de análise sociológica, $O$ campeador rio-grandense, segundo volume de seu Populaçóes meridionais do Brasil, ${ }^{1}$ um dos grandes clássicos da sociologia brasileira, fortemente influenciado pela etnografia raciológica de autores como Vacher de Lapouge e Gustave Le Bon. ${ }^{2}$

\footnotetext{
${ }^{1}$ Este segundo volume foi publicado postumamente, mesmo que inacabado, em 1952, e não é possível precisar a data de sua redação. O autor faz menção a ele em 1933 como uma de suas "obras em preparação". Em nota datada de 1948, Viana define o trabalho como um esboço inconcluso, mencionando a necessidade de revisão e de incorporação de estudos mais recentes sobre a sociedade sul-rio-grandense. Estes aspectos devem ser levados em conta na leitura do presente trabalho, devendo-se também manter em mente os objetivos particulares da leitura que realizamos neste artigo. FARIA, Luiz de Castro. Oliveira Vianna. De Saquarema à Alameda São Boaventura, 41 - Niterói. O autor, os livros, a obra. Rio de Janeiro: Relume Dumará, 2002, p. 93-95.

${ }^{2}$ No livro Raça e assimilação, publicado em 1932, o autor defende as teorias científicas raciais contra as novas tendências dos estudos sociológicos que as desautorizavam, reafirmando sua validade, em particular no estudo de países mestiçados como o Brasil. Os analistas da obra sociológica de Oliveira Viana observam o progressivo enfraquecimento do argumento raciológico em sua obra. CARVALHO, José Murilo de. A utopia de Oliveira Viana. Estudos Históricos, Rio de Janeiro: Fundação Getulio Vargas, v. 4, n. 7, p. 83-99, 1991. Sobre o tema, ver MURARI, Luciana. Messianismo e catástrofe. Algumas inflexôes políticas do debate raciológico brasileiro nas obras de Sílvio Romero, Nina Rodrigues e Oliveira Vianna. Agália, v. 8, n. 1, p. 103-128, 2013.
} 
O projeto intelectual esboçado por Viana em sua primeira obra rejeitava o pressuposto da uniformidade do povo brasileiro, que, segundo ele, conduzia os pensadores do seu tempo a buscar definir o Brasil como um todo único e homogêneo. ${ }^{3}$ Para tanto, o autor lança mão do princípio organicista - generalizado nas ciências humanas durante a vigência do cientificismo - de que condiçóes geográficas diversas conduziriam à formação de sociedades diversas, dado que a vida do homem é compreendida como parte do processo genérico de evolução natural. ${ }^{4}$ De acordo com Viana, a influência dos habitats ao longo do tempo, somada a fatores étnicos e civilizacionais, foi um forte determinante do processo histórico brasileiro, conduzindo à formação de três grandes regiôes e três grandes tipos humanos regionais no país: o matuto no centro-sul, o sertanejo no Norte, e, no extremo Sul, o gaúcho. O tipo representativo das regióes de cobertura florestal do núcleo mais dinâmico do país, equivalente aos estados do Rio de Janeiro, São Paulo e Minas Gerais, seria o único verdadeiramente nacional, pois esta região foi predominante na história do país, centro político-administrativo de onde derivaram as diretrizes de governo. Os gaúchos, habitantes da regiáo sulina de campos, têm sua especificidade explicada pela modelagem do meio físico do pampa, assim como pela influência da base econômica da pecuária e da história dos conflitos platinos. Já o tipo sertanejo, que teria como principal representante o cearense das caatingas, é um tipo pastoril cujas condições de desenvolvimento seriam ditadas pelas condiçôes específicas do meio físico rústico do semiárido. 5

Observe-se, portanto, que os referenciais que conduzem o pensamento de Oliveira Viana movimentam-se entre o âmbito nacional e o regional. Na obra do autor, persiste o dilema entre o reconhecimento da diversidade interna, legível nesta caracterização do homem rural brasileiro, por um lado, e a busca de elementos culturais, sociais, étnicos que permitissem supor uma idiossincrasia nacional, de outro. É a partir de um eixo de poder identificado com as elites hegemônicas que esta relação regional-nacional se resolve - como, em geral, se observa na história dos movimentos nacionalistas ${ }^{6}$ — através da imposição de uma dada

\footnotetext{
${ }^{3}$ Em sua conceituação convencional, as naçôes modernas formam unidades linguísticas, religiosas, étnicas. Em função disto, os intelectuais que debatem o problema nacional assumiram a tarefa de definir um tipo étnico capaz de representar as idiossincrasias de uma nacionalidade. Ao fim, o pressuposto de homogeneidade sobreleva a consideração da diversidade, retornando ao que Homi Bhabha define como a visão pedagógica da nação, o "muitos como um", produto de "teorias orgânicas do holismo da cultura e da comunidade [defendidas por] por teóricos que tratam gênero, classe ou raça como totalidades sociais que expressam experiências coletivas unitárias". BHABHA, Homi K. DissemiNação. O tempo, a narrativa e as margens da naçáo moderna. In: BHABHA, Homi K. O local da cultura. Tradução de Myriam Ávila, Eliana Lourenço de Lima Reis, Gláucia Renate Gonçalves. Belo Horizonte: Editora UFMG, 1998, p. 198-238. p. 203.

${ }^{4}$ SCHLANGER, Judith. Les métaphores de l'organisme. Paris: L'Harmattan, 1995.

${ }^{5}$ VIANNA, Oliveira. Populaçóes meridionais do Brasil. Populaçôes rurais do centro-sul. 5. ed. Rio de Janeiro: José Olympio, 1952a [1920], p. 13-17. v. 1.

${ }^{6}$ Isto é bastante nítido nos processos tardios de unificação empreendidos na Itália e na Alemanha na segunda metade do século XIX, impulsionados por elites regionais que lideraram o projeto político nacionalista. Vitorioso, este promoveu a ampla difusão de referências culturais, doravante tidas como "nacionais", na totali-
} 
região politicamente predominante como a mais tradicional, mais rica, mais representativa ou mais influente sobre o processo de formação nacional.

Na obra de Oliveira Viana, ao menos na primeira fase de sua atuação como publicista, ${ }^{7}$ a imagem de coesão necessária ao sucesso de um discurso nacionalista é recuperada pelo estabelecimento da ruralidade como determinante primordial dos traços distintivos da identidade social do país. Assim, para Viana, os tipos urbanos nada mais eram que variantes dos tipos rurais, estes sim decisivos para a caracterizaçáo da sociedade brasileira. Portanto, ao estudar o tipo gaúcho, o sociólogo tomou como referência o grupo social característico das tradicionais estâncias sulinas, com as quais é identificada a origem da identidade regional, e que seriam determinantes da inserçấo do Rio Grande do Sul na vida brasileira. Para analisar o modelo de argumentação adotado pelo sociólogo, é imprescindível compreender como a caracterização deste grupo humano estabeleceu-se na vida cultural brasileira, e como sua imagem chegou a Oliveira Viana.

\section{A identidade e a diferença}

Em célebre ensaio, Augusto Meyer $^{8}$ descreveu o lento processo histórico de transformação do sentido da palavra "gaúcho". Durante o século XVIII e até o início do século XIX, ela definia o tipo aventureiro voltado ao furto, ao contrabando ou ao coureamento, agregado às tropas em missóes esporádicas relacionadas com os conflitos de fronteira, ou contratados para a prestação de serviços ocasionais pelos proprietários. O termo "gaúcho", relativo aos mestiços indígenas, nômades por natureza, assumia uma conotação, portanto, inteiramente depreciativa, num contexto em que a extrema concentração da propriedade territorial e os

dade do território. No caso da Itália, o Piemonte assumiu a frente do processo em nome de um nacionalismo ancorado na imagem do Império Romano, e apenas cerca de 2,5\% da população falavam o idioma italiano quando da unificação do país. No caso da Alemanha, a liderança prussiana ditou os rumos do país unificado. HOBSBAWM, Eric John Ernest. Naçôes e nacionalismo desde 1780. 3. ed. Tradução de Maria Celia Paoli e Anna Maria Quirino. Rio de Janeiro: Paz e Terra, 2002.

${ }^{7}$ Em seu estudo sobre o conjunto da obra de Oliveira Viana, Luiz de Castro Faria observou uma inflexão na obra do autor a partir dos anos 1930, quando ele se coloca a serviço da política estatal de normatização das relaçôes de trabalho, e passa a se dedicar mais intensamente a estudos sobre instituiçôes, prática política e legislação. FARIA, Luiz de Castro. Oliveira Vianna. De Saquarema à Alameda São Boaventura, 41 - Niterói. O autor, os livros, a obra, op. cit., p. 30-31. Ao mesmo tempo, o autor acabou por abandonar o ideal de um patriarcalismo rural brasileiro e acaba por convencer-se de que o futuro conduzia à sociedade industrial, de modo que os temas ligados ao mundo rural perdem relevância em sua obra. CARVALHO, José Murilo de. A utopia de Oliveira Viana, op. cit., p. 94.

${ }^{8}$ Augusto Meyer (1902-1970): poeta, jornalista e ensaísta nascido em Porto Alegre, tornou-se um dos mais ativos adeptos do modernismo no Rio Grande do Sul. Foi membro da Academia Brasileira de Letras e, próximo ao grupo de Getúlio Vargas, assumiu a organização do Instituto Nacional do Livro, que dirigiu por cerca de trinta anos. ACADEMIA BRASILEIRA DE LETRAS. Augusto Meyer. Biografia. Disponível em: $<$ http://www.academia.org.br/academicos/augusto-meyer/biografia >. Acesso em: 21 jul. 2015. 
conflitos comerciais com a regiâo platina os condenavam a uma condição marginal face ao mundo da lei, do trabalho regular e da efetiva ocupação da terra.

Em meados do século XIX, entretanto, as transformaçôes sociais relacionadas com a intensificação e a organização das atividades produtivas e dos esforços de defesa do território agenciam uma gradativa positivação do termo. Aquele tipo social passou a ser incorporado de forma mais sistemática à rotina das estâncias e aos conflitos bélicos e, à medida que atendia a demandas sociais mais prementes e constantes, o tipo gaúcho começou a ser valorizado por atributos de fato relacionados com sua vida marginal, mas então socialmente convenientes: a destreza nas lides campeiras e na guerra. Isto o convertia em duplo personagem, peão em tempos de paz e soldado em tempos de confronto. Daí em diante, a palavra "gaúcho" se vê nobilitada a ponto de se tornar um gentílico definidor da população sul-rio-grandense, revertidos seus aspectos degradantes em encomiásticos: o ócio em liberdade, a violência em bravura, a rebeldia em altivez. A transformação da palavra denota, como demonstra o autor, a romantização do antigo elemento social do Rio Grande, processo que acaba por desfigurar a história em favor da criação de um mito de longa duração. ${ }^{9}$ O texto de Meyer é fundamental para se observar as possibilidades de manipulaçáo dos dados da realidade objetiva e da observação histórica de acordo com uma certa operacionalidade ideológica: neste caso, o enobrecimento da virtude bélica capaz de cooptar a população rural em torno de objetivos defensivos e de apoio à hegemonia das classes proprietárias.

O gaúcho heroicizado emergiria na literatura brasileira em 1870, pela pena de José de Alencar, que o tomou como o primeiro tipo regional a ser explorado no contexto de seu projeto regionalista, embasado pelo discurso, mais tarde convertido em fundamentação programática, da tendência dos povos jovens à imitação do estrangeiro, da dissolução dos costumes legitimamente nacionais sob o influxo da civilização europeia, e da busca de exploração das verdadeiras reservas de brasilidade representadas pelos tipos rurais. ${ }^{10} \mathrm{O}$ gaúcho de Alencar nada mais é do que uma das variantes dos tipos heroicos que povoam suas narrativas românticas, alimentado por doses extras de galhardia e belicosidade. Manuel Canho, protagonista de $O$ gaúcho (1870), reúne os clássicos atributos do homem do pampa: agilidade, vigor físico, rigidez moral, estrita lealdade à honra familiar, instinto vingativo, bravura e ímpeto guerreiro, apego desmedido aos cavalos, ódio ao castelhano e obediência irrestrita ao chefe militar — no caso, Bento Gonçalves, figura do herói galante conjugada à do "homem superior":

Os homens o adoravam; as mulheres o admiravam. $\mathrm{O}$ mais sacudido rapaz achava coisa muito natural que as moças bonitas chegassem à janela para ver passar o elegante velho, com seu talhe alto e espigado, e seu peito amplo e bombeado como a petrina do brioso ginete.

\footnotetext{
${ }^{9}$ MEYER, Augusto. Gaúcho, história de uma palavra. In: Prosa dos pagos. 1941-1959. Rio de Janeiro: Livraria São José, 1960, p. 9-42. . Sonhos d'ouro. São Paulo: Ática, 1981 [1872], p. 7-12. 
Sensível a essa fineza do belo sexo, o veterano alisava o bigode grisalho, pagando com um sorriso os olhares coados pelas rótulas. Ao mesmo tempo consolava os rapazes, fazendo-lhes um aceno com a mão, ou dirigindo-lhes algum dito picaresco. ${ }^{11}$

A comunicação com a história regional é, então, estabelecida como verdadeiro princípio de uma literatura que, desde seus primórdios, dialoga com o passado, seja como testemunho da memória social, escrita a partir de experiências individuais exemplares, seja como coadjuvante da escrita historiográfica, ao fixar o sentido dos fatos, mormente a consagração dos heróis, a defesa do ideal civilizatório representado pelo respeito aos valores e convençóes sociais e à lei e, sobretudo, a inquestionável fidelidade ao Brasil, que espanta o fantasma separatista ao afirmar a Revolução Farroupilha como manifestação de um ideal libertário em última instância patriótico. Dá exemplo disto a curiosa matemática nacionalista do Bento Gonçalves de José de Alencar, dirigindo-se ao caudilho uruguaio Juan Lavalleja: "Em outro momento e outro lugar, eu lhe mostraria que um brasileiro não vale um, mas dez homens, enquanto são precisos dois castelhanos para fazer meio brasileiro". ${ }^{12} \mathrm{O}$ estrangeiro é posto, neste momento, a referendar a lealdade do líder farroupilha ao Brasil, de maneira que é a figura do outro que unifica o nacional em face do regional, e tira deste qualquer sentido de dissidência.

Foi sob a inspiração de Alencar, dos poetas do romantismo brasileiro e do romance histórico de Alexandre Herculano que a literatura do Rio Grande do Sul começou a produzir sua autoimagem. ${ }^{13} \mathrm{O}$ vaqueano José de Avençal, de Apolinário Porto Alegre, ${ }^{14}$ no romance surgido em 1872, reúne as qualidades marciais que consagraram o tipo gaúcho na literatura regionalista, combinadas com as virtudes do herói romântico agradável ao público urbano, como homem gentil, sensível e introspectivo, que "nos combates era o delírio personificado" e, simultaneamente, da guerra "saía sempre incólume, ainda que pesaroso". O José de Avençal de Apolinário é um cognato do Manuel Canho de Alencar, reproduzindo suas virtudes, motivações e lealdades. Cabe ressaltar dois aspectos da obra do escritor rio-grandense dotados de significativa relevância ideológica. Em primeiro lugar, afirma-se que as qualidades que definiam seu protagonista eram — com a exceção de seu misterioso ar melancólico — comuns não apenas ao homem da campanha, mas ao habitante do Rio Grande do Sul, em geral:

\footnotetext{
${ }^{11}$ ALENCAR, José de. O gaúcho. Porto Alegre: L\&PM, 2002 [1870], p. 24-25.

${ }^{12}$ ALENCAR, José de, op. cit., O gaúcho, p. 31.

${ }^{13}$ CÉSAR, Guilhermino. História da Literatura do Rio Grande do Sul (1737-1902). 3. ed. Porto Alegre: Instituto Estadual do Livro, Corag, 2006. c. XI. CHAVES, Flávio Loureiro. Simóes Lopes Neto. 2. ed. revista. Porto Alegre: Ed. da UFRGS, Instituto Estadual do Livro, 2001. c. 1.

${ }^{14}$ Apolinário Porto Alegre (1844-1904): educador, escritor e jornalista nascido em Rio Grande (RS), foi um dos fundadores da Sociedade Partenon Literário, entidade cultural e beneficente difusora do ideário romântico e das causas republicana e abolicionista no estado. LAZZARI, Alexandre. Entre a grande e a pequena pátria: letrados, identidade gaúcha e nacionalidade (1860-1910). Tese (doutorado) - Programa de Pós-Graduação em História, Unicamp, Campinas, 2004, p. 59-67.
} 
Os principais traços característicos de fisionomia que esboçamos de leve são tão reais que os encontramos a cada passo em nossa Província, desde o posteiro até o senhor da estância, desde a existência errante do tropeiro até a existência sedentária do guasqueiro ou trançador de lonca. ${ }^{15}$

Neste momento, o autor consagra o gaúcho como sinônimo do rio-grandense, colando a representação do homem às fronteiras político-administrativas provinciais — o que autoriza o uso do termo como gentílico. Em segundo lugar, Apolinário Porto Alegre opera prodígio equivalente, acenando para o caráter democrático da sociedade aí estabelecida, apagando tanto as diferenças locais, no interior do território da província, quanto as diferenças de classe, no interior de sua estrutura social. O tipo transcendente então criado prestava-se com perfeição a um discurso nivelador em que o Rio Grande do Sul apresentava-se como uma causa e de um destino comuns.

A criação literário-ideológica do gaúcho faria longa tradição no Rio Grande do Sul, e se comunicaria à cultura do país de forma algumas vezes inesperada, como é o caso d'Os sertóes, de Euclides da Cunha. O próprio Augusto Meyer, ao historiar a palavra "gaúcho", dedicou-lhe brilhante crítica, ao observar a sucessão de clichês mobilizados pelo escritor para compor o gaúcho como a perfeita antítese do sertanejo, "acumulação quase caricata de adjetivos" contrapostos para criar efeito estético, mas vazia de sentido e desprovida de qualquer fundamento sociológico. ${ }^{16}$ Vale observar, no entanto, mesmo em função da forte influência intelectual exercida pelo escritor, alguns aspectos importantes desta antítese. Em primeiro lugar, devemos ter em mente a ambiguidade com que Euclides da Cunha aborda o sertanejo em sua obra, e não apenas neste trecho, embora análises apressadas tendam a definir a questão fazendo uso imediato da famosa sentença, "antes de tudo, um forte”. Em sua descrição do sertanejo, nada denuncia constância, na "intercadência impressionadora entre extremos impulsos e apatias longas”. É difícil imaginar como, passando dois terços de sua existência em uma "rede amolecedora", o sertanejo poderia ser capaz de exibir tamanha tenacidade e energia, convertendo-se num "centauro bronco" quando sua força física era demandada para alguma tarefa excepcionalmente penosa, após a qual decairia, novamente, "com a aparência triste de um inválido esmorecido". ${ }^{17}$ Ao contrário, ao referir-se ao gaúcho, não há dubiedade, e sim um tipo definitivo, garboso, íntegro e heroico, que não fica muito a dever à idealização romântica de José de Alencar e seus epígonos: nenhum dos predicados atribuídos a ele é de fato negativo.

Resta ainda lembrar que este contraste, que coloca o tipo gaúcho em evidente vantagem, é também ditado pelo que seria a harmônica relação do homem sulino com o meio natural,

\footnotetext{
${ }^{15}$ PORTO ALEGRE, Apolinário. O vaqueano: narrativa. Porto Alegre: Livraria do Globo, 1927 [1872].

${ }^{16}$ MEYER, Augusto. Gaúcho, história de uma palavra, op. cit., p. 38.

${ }^{17}$ CUNHA, Euclides da. Os sertóes. Ed. crítica. São Paulo: Brasiliense, 1985 [1902], p. 181.
} 
à qual se opõe a dura "luta pela vida" do sertanejo. Enquanto o gaúcho seria a verdadeira expressão do domínio do homem sobre um meio que fornece a ele completa liberdade e suporte, o sertanejo, "perfeita tradução moral dos agentes físicos da sua terra", sobreviveria penosamente a uma árdua e sempre incompleta adaptação a um espaço rude e hostil: enquanto um se diverte, o outro se exaure. ${ }^{18}$ Além disto, embora seja o único tipo regional brasileiro diretamente comparado com o sertanejo n'Os sertôes, o gaúcho não é citado como uma das etnias rurais obsoletas que o escritor vê condenadas à próxima extinção no Brasil, por sua pretensa incapacidade de progresso: nesta condição são arrolados, juntamente com os sertanejos, os tabaréus e os caipiras..$^{19} \mathrm{O}$ homem gaúcho vê-se assim desassociado das imagens de exaustão física, degeneração racial e espírito melancólico em geral atribuídas ao homem do meio rural brasileiro, consagrando-se como um tipo cuja descrição alimenta-se de seu oposto:

As suas vestes são um traje de festa, ante a vestimenta rústica do vaqueiro. As amplas bombachas, adrede talhadas para a movimentação fácil sobre os baguais, no galope fechado ou no corcovear raivoso, náo se estragam em espinhos dilaceradores de caatingas. $\mathrm{O}$ seu poncho vistoso jamais fica perdido, embaraçado nos esgalhos das árvores garranchentas. E, rompendo pelas coxilhas, arrebatadamente na marcha do redomão desensofrido, calçando as largas botas russilhonas, em que retinem as rosetas das esporas de prata; lenço de seda encarnado, ao pescoço; coberto pelo sombreiro de enormes abas flexíveis, e tendo à cinta, rebrilhando, presas pela guaiaca, a pistola e a faca - é um vitorioso jovial e forte. O cavalo, sócio inseparável desta existência algo romanesca, é quase objeto de luxo. Demonstra-o o arreamento complicado e espetaculoso. O gaúcho andrajoso sobre um "pingo" bem aperado está decente, está corretíssimo. Pode atravessar sem vexames os vilarejos em festa. ${ }^{20}$

O pensamento de Euclides da Cunha converge neste ponto com o do jovem Alcides Maya, ${ }^{21}$ que, já antes da publicação d'Os sertôes, refletia sobre a fixação da identidade regional gaúcha, conclamando o Rio Grande do Sul a ocupar sua posição de "vanguarda do Brasil", não exatamente por suas virtudes bélicas, mas pela canalização de suas energias combativas em direção à modernização do país. ${ }^{22}$ No artigo "O Rio Grande Mental", es-

\footnotetext{
${ }^{18}$ Ibidem, p. 183.

${ }^{19}$ Ibidem, p. 85.

${ }^{20}$ Ibidem, p. 182.

${ }^{21}$ Alcides Maya (1848-1944): escritor, político e jornalista nascido em Sáo Gabriel (RS). Foi membro da Academia Brasileira de Letras e deputado pelo Partido Republicano Rio-grandense (1918-1931). Mais tarde, colaborou com Getúlio Vargas. Como jornalista, contribuiu com diversos periódicos no Rio Grande do Sul e no Brasil. Publicou o romance Ruinas vivas (1910) e as coletâneas de contos Tapera (1911) e Alma bárbara (1922). ALMEIDA, Marlene Medaglia. Na trilha de um andarengo. Alcides Maya (1877-1944). Porto Alegre: Mercado Aberto, Edipucrs, 2004.

${ }^{22}$ MAYA, Alcides. Pelo futuro. Porto Alegre: Franco \& Irmão, 1897. p. 113.
} 
crito nos últimos anos do século XIX, Maya defende a capacidade do estado de constituir uma cultura própria e original, apesar de um passado belicoso que por longo tempo teria desviado sua vitalidade em direção à guerra. Neste ponto, o tipo rio-grandense é contraposto ao platino, seu habitual antípoda, que se teria deixado contaminar pela luta caudilhesca e desprovida de ideais, enquanto o Rio Grande do Sul mantivera inquestionada sua lealdade ao Brasil, causa suprema de sua mobilização para guerras sempre legítimas.

Simultaneamente a esta afirmação do sentido brasileiro da história do Rio Grande do Sul, Maya estabelece a superioridade do rio-grandense também sobre os demais tipos regionais do país, pois "o mestiço mais característico da história americana é o gaúcho", afirma ele, argumentando que apenas o mameluco paulista, ou seja, o bandeirante, teria uma história comparável à sua. ${ }^{23}$ No entanto, essa, como as demais etnias do interior brasileiro, ter-se-ia desvirtuado e desaparecido, sob o influxo da imigração. Já no caso do gaúcho, o autor reforça a ideia de sua integridade física superior e, mesmo supondo sua extinção como tipo étnico, conclui que ele manteria incólume sua idiossincrasia, definitivamente incorporada pelo homem rio-grandense:

O mameluco passou; ao contato das levas constantes de imigrantes desfiguram-se e passam, na vida do interior brasileiro, os representantes da mestiçagem nacional. O gaúcho no Rio Grande não passa.

Desaparecesse o seu tipo fisionômico, tombassem em desuso os seus costumes, os seus trajes, os seus trabalhos, ainda assim, ele ficaria na alma do Rio Grande. O espírito rio-grandense é fundamentalmente gaúcho em algumas de suas notas. ${ }^{24}$

Ecoando a identificação entre gaúcho e rio-grandense, ainda que reiterando o sentido diverso que os dois termos ainda guardavam, o autor alega que a base da formação da identidade regional estaria em uma mentalidade específica criada sob o influxo do ciclo bélico da campanha, uma integridade resistente à mudança histórica que o autor não reconhece nos demais mestiços brasileiros. Embora baseada no fundamento orgânico — a integridade da "raça" - esta identidade seria capaz de transcendê-la e tornar-se a raiz de uma liderança de ordem moral. $\mathrm{O}$ autor, neste sentido, nega o argumento belicista ao mesmo tempo que o afirma como raiz da vitalidade física e espiritual do gaúcho, e fonte privilegiada para a imaginação literária; recusa o determinismo mesológico para, em seguida, afirmar a superioridade do meio físico do estado sobre o do restante do país, impondo-o como espaço privilegiado para a criação cultural; da mesma forma, afirma a integridade étnica do gaúcho, para em seguida dispensá-la em prol de uma identidade espiritual mais relevante. A partir desta

\footnotetext{
${ }^{23}$ MAYA, Alcides. O Rio Grande mental. In: Através da imprensa. Porto Alegre: Octaviano Borba \& Irmão, 1900, p. 93-106. p. 102.

${ }^{24}$ Ibidem, p. 103-104.
} 
mistura eclética de retórica romântica e argumentação científica, Alcides Maya constrói um discurso mobilizador colado à interpretação do passado, mas devotado à atribuição de um novo sentido à história do Rio Grande do Sul, através de uma reformulação da herança bélica em que esta perde seu sentido literal, convertendo-se em um espírito de comando que constrói a ideia messiânica de uma missão a ser cumprida pelo estado no país.

A obra ficcional de Maya distanciou-se, entretanto, de seu projeto inicial, à medida que o autor se dedicou a uma reflexão angustiosa sobre o fim do ciclo bélico da história do Rio Grande e sobre a decadência do tipo humano convencional do pampa - o que, é claro, dependia do prévio endosso ao modelo, ao se prender a um passado idealizado. ${ }^{25}$ Em Ruínas vivas, os personagens centrais são aficionados pela guerra — que era memória e experiência para o velho Chico Santos, mas apenas narrativa para seu neto Miguelito. Incompatíveis com a modernidade, ambos são encarnaçóes evidentemente anacrônicas do gaúcho tradicional. ${ }^{26} \mathrm{~A}$ força crítica da obra de Maya permite avaliá-lo como um romance à parte dentro da história do gauchismo, incompatibilizando-o com os propósitos mobilizadores e autocongratulatórios que seriam capazes de definir parte significativa dessa produção literária. ${ }^{27}$

O jornalista e escritor regional Roque Callage ${ }^{28}$ é outro exemplo da prática de valorização da identidade gaúcha a partir de uma perspectiva racialista e comparativa. Na visão de Callage, o tipo brasileiro mais representativo era o caboclo, exemplar, no entanto, de uma formação étnica imperfeita e ainda em curso. Sua descrição do mestiço indígena sertanejo recorda as de Monteiro Lobato, em sua descrição do caipira, e Euclides da Cunha, em sua descrição do homem do semiárido, sem a relativização que o higienismo trouxe ao primeiro e sem a observação de caracteres positivos na gênese do homem do sertão, como no caso do segundo — esses autores são, aliás, citados pelo próprio Callage.

As expressóes que o escritor utiliza, em texto de 1920, para definir o sertanejo do Norte e o caipira, não dão margem a sutilezas: "única mancha que afeia a beleza incomparável do

\footnotetext{
${ }^{25}$ Em seu estudo clássico sobre o regionalismo gaúcho, Lígia Chiappini tratou desta questão como o embate entre o "gaúcho herói" e o gaúcho-Quixote. Embora reconheça a natureza crítica da obra de Maya, a autora - como em geral a historiografia literária do Rio Grande do Sul - argumenta que o culto do passado corresponde, em sua obra, a uma tentativa de dissimular as contradiçôes sociais, sublimando a condição de marginalidade do trabalhador da regiáo pastoril. Isto obsta o reconhecimento da força questionadora de seus textos. LEITE, Lígia Chiappini Moraes. Regionalismo e modernismo. O caso gaúcho. São Paulo: Ática, 1978. ${ }^{26}$ MAYA, Alcides. Ruinas vivas. 2. ed. Porto Alegre: Movimento; Santa Maria (RS): Editora UFSM, 2002.

${ }^{27}$ Esta representação da decadência do tipo regional acabou por causar espécie. Em célebre polêmica jornalística ocorrida entre 1925 e 1926, Moysés Vellinho, que militava nas mesmas hostes governistas de Alcides Maya, criticava o escritor pelo que seria o pessimismo de sua literatura. "A capacidade heroica do gaúcho é sempre a mesma", escrevia Vellinho, defendendo a continuidade do espírito gaúcho em sua operacionalidade ideológica, e se contrapondo, assim, à implosão do mito operada por Maya. ARINOS, Paulo [Moysés Vellinho]. O papel da nova geração. In: CHAVES, Flávio Loureiro (Org.). O ensaio literário no Rio Grande do Sul (1868-1960). Rio de Janeiro: Livros Técnicos e Científicos; Brasília: INL, 1979, p. 85-87.

${ }^{28}$ Roque Callage (1888-1931): escritor e jornalista nascido em Santa Maria (RS), foi um dos mais populares cronistas porto-alegrenses dos anos 1920. Escreveu também ensaios sobre temas regionais e contos ficcionais gauchescos. MACHADO, Propício da Silveira. Roque Callage: vida, obra e antologia. Porto Alegre: UFRGS, 1975.
} 
sertão", "o esboço de um derrotado", "um vencido antes da luta”, "figura sorna" que não teria experimentado nenhuma evolução ao longo da história brasileira, e que não teria sabido converter em riqueza material a imensa fonte de prosperidade representada pelas matas brasileiras. O sertanejo - de forma indiferenciada, o do centro-sul e o do atual Nordeste - seria apenas um exemplo específico no caso geral da mestiçagem no país, mescla de tipos "inferiores" iniciada com o consórcio entre os criminosos degredados de Portugal e os tipos nativos, "mistura mórbida" que teria o caboclo como resultado. Inversamente, em sua opinião, o tipo regional gaúcho é um depositário das mais nobres virtudes, embora formado pelos mesmos elementos raciais — indígena e "branco suspeito".

Mas o habitante da campanha, o "índio", o "chiru”, com quem ele próprio arrogantemente se acoima, é na aparência o mesmo caboclo do norte na cor bronzeada do físico. No fundo, porém, a diferença entre ambos é latente. Aquele vive em si mesmo, indeciso, de olhar apagado, meio morto, sem ação. Este, ao contrário, abrange horizontes mais amplos; não vacila, não teme, não titubeia. Em todas as suas atitudes é destro, é ágil, é decisivo. A planura, a guerra, o cavalo, ensinaram-lhe a agir, a correr. Dir-se-ia mesmo que entre ele e o "pingo" se firmou uma aliança de marcha precipitada, para frente. Essas características incisivas, a surgir em relevos de legenda, elevaram até bem pouco o homem, na mitologia americana, à altura dos Centauros. ${ }^{29}$

Eis, reciclado, o mito do "centauro dos pampas", mais uma vez referendado pela afirmação de uma alteridade radical do gaúcho em relação ao caboclo. A explicação do autor para tamanha diferença entre os tipos mestiços é simplória e lança raízes na teoria mesológica que havia aportado ao Brasil cinquenta anos antes: ${ }^{30}$ no ambiente de florestas, a abundância e a acessibilidade dos meios de sobrevivência favoreceria o ócio. $\mathrm{O}$ gaúcho, ao contrário, seria o fruto de outro ambiente, mais saudável, porém (e porque) menos abundante. Além disto, seus horizontes seriam amplos, o que daria a ele perspectivas seguras, espantando o temor. "O piraguara sertanista dos roçados fala de cócoras, tímido, indeciso, num resfolegar de raça desfibrada; o 'guasca' campeiro, responde de pé, ligeiro e petulante." ${ }^{1}$ A lida na guerra e no

${ }^{29}$ CALLAGE, Roque. Índio $\times$ caboclo. In: Terra natal. Aspectos e impressōes do Rio Grande do Sul. Porto Alegre: Barcellos, Bertaso \& C., 1920, p. 11-15. p. 14-15.

${ }^{30}$ No caso, fazemos referência à chamada "geração de 1870 ", grupo heterogêneo de intelectuais que, a partir do questionamento do ecletismo filosófico romântico ainda predominante nas instituiçóes de ensino superior do país, assimila as diversas correntes do naturalismo cientificista surgidas na Europa nas décadas anteriores. Uma das primeiras dessas correntes que aportaram no país foi o determinismo mesológico de Henry Thomas Buckle, ao qual se seguiram autores positivistas, evolucionistas e darwinistas sociais, em suas diversas linhas - o racismo científico, a antropologia social, a criminologia, o positivismo jurídico, entre outras. Sobre o tema, ver, por exemplo SCHWARCZ, Lilia Moritz. O espetáculo das raças: cientistas, instituiçôes e questão racial no Brasil (1870-1930). Sáo Paulo: Companhia das Letras, 1993. CANDIDO, Antonio. O método crítico de Sílvio Romero. São Paulo: Edusp, 1988. MURARI, Luciana. Brasil: ficção geográfica. Ciência e nacionalidade no país d'Os sertôes. São Paulo: Anablumme, Belo Horizonte: FAPEMIG, 2007.

${ }^{31}$ CALLAGE, Roque, Índio $\times$ caboclo, op. cit., p. 15. 
campo e a intimidade com o cavalo na vida do gaúcho teriam favorecido o desenvolvimento de um físico ágil e de um espírito intrépido, dotado de iniciativa e de constância. Soma-se a essas ideias a observação da influência positiva da imigração europeia, que estaria criando um novo tipo, "uma nova energia triunfante": o colono gaúcho, que substituíra a guerra pelo esforço sistemático em busca do conforto material.

A literatura ficcional de Callage se dividiria entre a retomada da visão crítica e modernizante de Alcides Maya, o discurso saudosista face à derrocada da tradição campeira e a influência deletéria das inovaçôes tecnológicas sobre as práticas, comportamentos e sensibilidades do gaúcho típico. Para além da tradição, existiria, no entanto, uma essência atemporal capaz de manter a inteireza do tipo gauchesco na modernidade, mesmo que este fosse suplantado, como inevitavelmente aconteceria, pelo imigrante europeu. Reedita-se, assim, o tema alcidiano da conversão do gaúcho tradicional (o peão trabalhador das estâncias do sul do estado) no gaúcho moderno, qual seja, o sul-rio-grandense, herdeiro de suas tradiçóes, sua moralidade e seu modo de ser.

\section{O campeador rio-grandense}

Em que pese a lamentação pela perda do universo gauchesco da campanha, contrastada com a vitalidade das populaçóes adventícias de origem italiana e alemã, Roque Callage reafirmava sua confiança de que "estava ali um Rio Grande novo para ele, mas que seria o Rio Grande de amanhã, desdobrado em novas forças, em novas energias, em novas atividades, em novas expressôes de trabalho". ${ }^{32}$ Essa citação origina-se de um conto intitulado "Vida nova" e dedicado a Oliveira Viana: Viana elaborou uma das mais notáveis expressôes da contraposição entre o tipo regional rio-grandense e os demais grupos étnicos brasileiros, com evidente vantagem do primeiro. Vê-se, entáo, como no caso de Euclides da Cunha, que o ufanismo gauchesco não é exclusivo dos intelectuais do Rio Grande do Sul.

Todos os escritores citados têm em comum a ênfase na centralidade do meio físico do pampa na formação da sociedade gaúcha, a "alma pampa", de José de Alencar. ${ }^{33}$ E compartilham também a mesma mirada literária medievalizante em direção ao personagem. A caracterização do tipo regional gaúcho em oposição ao matuto do centro-sul, rapidamente esboçada no clássico primeiro volume das Populaçôes Meridionais do Brasil, foi aprofundada por Oliveira Viana no segundo volume da obra, raramente estudado. Este trabalho sobre o campeiro rio-grandense condensa, de forma exemplar, a convergência entre imaginação literária, análise histórica, argumentação etnográfica e discurso doutrinário, característica do

\footnotetext{
${ }^{32}$ CALLAGE, Roque. Lida nova. In: Quero-quero. Scenas crioulas. Porto Alegre: Livraria do Globo, 1927, p. 117-122. p. 121.

${ }^{33}$ ALENCAR, José de, O gaúcho, op. cit., p. 16.
} 
estilo do autor nessas obras sobre a formação da população brasileira. Na obra consagrada ao tipo popular gaúcho, este é representado em conformidade com um modelo já operativo na cultura rio-grandense e brasileira. Embora o discurso de Oliveira Viana pretendesse ser, antes de tudo, uma análise científica embasada na teoria sociológica racialista, as fontes em que ele se apoia são bastante restritas, tanto quantitativa quanto qualitativamente, o que faz com que sua obra recaia num subjetivismo náo muito distinto do que se apresenta nas obras ensaísticas e romanescas já citadas, sendo a partir daí elaborado um discurso encomiástico colado a um ideal político que o autor vê materializado na formação histórica do Rio Grande do Sul.

Para o jurista fluminense, a condição de fronteira desprotegida face às ameaças externas foi uma fatalidade mesológica que lançou o civismo gaúcho à defesa intransigente de sua terra. Na ausência de obstáculos naturais à invasão estrangeira, estabeleceu-se uma condição de guerra constante em campo aberto, traduzida por Oliveira Viana como uma verdadeira luta entre a barbárie caudilhesca dos platinos e a civilização dos gaúchos brasileiros, assentada em sólida disciplina militar. Derivada da peculiaridade geográfica que tornaria o território rio-grandense mais suscetível a invasôes, o esforço de guerra necessário à defesa das propriedades ter-se-ia estabelecido como elemento de organizaçáo da sociedade, conferindo aos variados grupos sociais uma direção conjunta nos esforços defensivos, ou seja, táticas sistematizadas que submetiam os lutadores convocados à defesa da terra - os estancieiros e seus sequazes - ao mando dos chefes militares. ${ }^{34}$

Excepcionalmente dotados para a luta pela vigorosa lida cotidiana na criação de gado, os milicianos campeiros submetidos à estratégia militar integravam-se, postula o sociólogo, a uma poderosa oligarquia armada, verdadeira classe dirigente da regiáo, capaz de exercer, em função do esforço comum de guerra, uma autoridade inquestionável sobre seus subordinados. Define-se, portanto, uma situação social caracterizada pela legitimação popular do poder, o que faz com que o homem do povo seja definido como um homem consciente de suas escolhas políticas, mas disciplinado por sua submissão voluntária à superioridade de um representante das elites proprietárias.

Isto somente seria possível porque a escolha destes chefes militares entre os estancieiros era conduzida segundo um processo de debate e eleição, de acordo com critérios meritocráticos que garantiriam o imediato referendo da população, não sendo outros senão a habilidade tática, a coragem e a capacidade de organização bélica. Repete-se, aqui, a mitologia do "homem superior" que, como já vimos anteriormente, está presente na literatura gauchesca desde José de Alencar. Numa guerra defensiva, diz Viana, os chefes assumem uma responsabilidade gravíssima, pois deles depende a posse do território e, por consequência, a sobrevivência do grupo social. Desta forma, opera-se o que seria uma seleção pela guerra: em combate, as virtudes de comando são explicitadas, permitindo entrever as qualidades de cada indivíduo, e apenas essas determinariam sua ascensão ao poder.

\footnotetext{
${ }^{34}$ VIANNA, Oliveira. Populaçôes meridionais do Brasil. v. 2. O campeador rio-grandense. Rio de Janeiro: José Olympio, 1952. c. IX. v. 2.
} 
Assim, no caso gaúcho, os líderes teriam assumido a responsabilidade de mobilizar o povo para o esforço de guerra, em "ebulição patriótica". Ao contrário, no sertão e no centro-sul do país, as chefias impunham-se pelo poder econômico ou pela tradiçáo familiar, e não pelas virtudes de liderança, assumindo a condição de mando sem que a população fosse chamada a se manifestar, o que obstava o desenvolvimento do espírito público, restritas as lealdades ao nível dos clãs locais. A organização social da região centro-sul seria, portanto, o principal fundamento da formação da política oligárquica que, na visão do autor, obstava a centralização do poder, tida como fator essencial para a afirmação dos interesses da nacionalidade e sua imposição sobre os interesses restritivos das regiôes.

Portanto, estudando a formação do gaúcho como um tipo social consagrado pela estabilidade de suas características morais e étnicas, Oliveira Viana caracteriza a guerra como uma escola de liderança em que os chefes desenvolviam seu sentido de autoridade e de comando, o que implicava, acentua ele, o fortalecimento da capacidade de repressáo, de imposiçáo da disciplina, de julgamento de condutas, e de determinação de penalidades, o que, segundo o autor, criava uma mentalidade insensível e brutalizada. Por outro lado, a coibição da sensibilidade é vista como necessária à formação do líder político e do estadista, atribuindo a ele "um temperamento admiravelmente adaptado ao exercício da autoridade". ${ }^{35}$ Como vemos, mesmo os atributos virtualmente negativos são positivados por essa tipificação que quase nada relativiza, ao construir a imagem do líder regional como uma figura dotada de atributos políticos superiores dentro da galeria de tipos brasileiros.

A essas virtudes eminentemente políticas o autor adiciona um elemento que já havia sido desenvolvido no primeiro volume da obra, qual seja, a solidariedade social inspirada na articulação de esforços em torno do objetivo comum de defesa contra as agressôes externas, mas também pelo que seria a própria essência das lidas do pastoreio. Os conflitos sociais são dissolvidos pela afirmação de um intrínseco igualitarismo, defendido em um capítulo intitulado "Origens pastoris da democracia rio-grandense". Vimos anteriormente como, na obra de Apolinário Porto Alegre, este mito da democracia gaúcha havia já se estabelecido como um dos pilares do gauchismo. A "tradição de igualdade e familiaridade entre patrôes e servidores" seria produto da natureza do trabalho no campo, que conferiria um aspecto democrático a esta sociedade, uma vez que a elegância, a destreza e o vigor exigidos pelos afazeres da estância dariam ao trabalho uma feição enobrecedora, capaz de congregar as diversas classes sociais. ${ }^{36}$ Ao contrário da natureza degradante do trabalho nos sertóes e no centro-sul seja pela brutalidade das tarefas, seja pelo "preconceito aristocrático" dos proprietários — no extremo sul, senhores e servos seriam efetivamente cooperantes no cotidiano das fazendas, e veriam no trabalho, enobrecedor e prazeroso, um exercício de altaneria.

\footnotetext{
${ }^{35}$ Ibidem, p. 204.

${ }^{36}$ Grifos do autor. Ibidem, p. 289. 
O pampa - com a sua amplitude, o seu desafogo, a sua horizontalidade, a sua vegetação graminosa - faz do trabalho pastoril um verdadeiro esporte. Diante do animal e do meio topográfico, o campeador gaúcho não está como o pastoreador dos sertôes. Em vez de caatingas bravias e repulsivas - a planície mansa, carinhosa, ilimitada, própria para as disparadas velozes ou as evoluçóes graciosas. [...] Essa planície assim desabrigada e livre representa, para os campeadores do sul, uma sugestão aliciante, um convite irresistível para o movimento, para as correrias, para as disparadas ao largo dos tabuleiros. Marchando para as rechãs em busca das manadas é como se caminhassem para a glória de um torneio; estrepitosos e comunicativos; proferindo palavrôes cabeludos; rindo, gritando, a galope, como um clã de centauros. ${ }^{37}$

Esta repetição do clichê do gaúcho mitológico não deve obscurecer o fato de que tais qualidades da formação da sociedade pecuária no Rio Grande do Sul não estão circunscritas ao contexto geográfico e histórico em que se criaram, ou seja, este ambiente simultaneamente pastoril e guerreiro não é visto como um começo, e sim como uma origem. Compreende-se o termo, no sentido conferido por Foucault, ${ }^{38}$ como forma de articulação do homem com o trabalho, a vida e a linguagem, que vieram antes dele e que, mesmo distantes, nunca estão totalmente ausentes. No entanto, esta origem, tão familiar quanto estranha, da qual nos aproximamos e nos afastamos continuamente, só pode ser acessada através de intrincadas mediaçôes dotadas de historicidade própria. Neste caso, estão aí identificados elementos que não exatamente buscam descrever o passado, mas que desenvolvem relaçóes peculiares com a temporalidade e a história, e exercem papéis dinâmicos no presente, incorporados ao projeto utópico de mudança social proposto por Oliveira Viana.

Para tanto, é necessário, de acordo com a visão de mundo do autor, conferir ao tipo gaúcho - democrático, respeitador da autoridade, disciplinado e solidário — um caráter étnico, atribuindo a ele não apenas determinados traços físicos como uma moralidade característica de sua constituição mental peculiar. Tanto Euclides da Cunha quanto Alcides Maya e Roque Callage participaram desta abordagem raciológica em que a biologia cruza o campo da identidade social. Na visão de Viana, "a fixidez dos caracteres culturais do grupo gaúcho" consagra-o como uma etnia constituída e estável, característica atribuída também aos sertanejos. ${ }^{39}$

Para exemplificar este argumento, Viana recorre a exemplos que denotariam a manifestação das habilidades marciais do rio-grandense em circunstâncias posteriores e totalmente descoladas do ambiente do pampa. Na conquista do Acre, a típica índole autoritária e a característica habilidade de congregação de grandes massas seriam identificáveis através da ação dos "caudilhos" do Exército, que teriam desenvolvido as estratégias e táticas vitoriosas

\footnotetext{
${ }^{37}$ Ibidem, p. 296-297.

${ }^{38}$ FOUCAULT, Michel. As palavras e as coisas. Uma arqueologia das ciências humanas. 8. ed. Trad. Salma Tanus Muchail. São Paulo: Martins Fontes, 2000, p. 256-257.

${ }^{39}$ VIANNA, Oliveira, Populaçôes meridionais do Brasil. v. 2, op. cit., p. 200.
} 
de campanha. Similarmente, na cidade mineira de Pitangui, a "enorme efervescência patriótica" concretizada no alistamento maciço de voluntários, quando da deflagração da guerra do Paraguai, é atribuída à liderança de um tenente gaúcho, que não apenas teria insuflado os ânimos, mas também organizado e treinado os "batalhóes patrióticos" — contrastantes com a indiferença generalizada das cidades vizinhas.

Do ponto de vista da descrição físico-biológica da etnia gaúcha, Viana lança mão das teorias raciais para caracterizar as superiores "forças de higidez e eugenismo" do tipo gaúcho. Segundo ele, enquanto outros tipos regionais brasileiros teriam sofrido uma grande influência da população de origem negra, no extremo sul essa influência teria sido consideravelmente menor. O principal fator diferenciador do homem gaúcho seria a miscigenação de índios minuanos, tapes e charruas, "bravios e robustos", com povoadores arianos de origem açoriana, paranaense ou paulista. Principalmente entre as classes mais altas, os brancos preponderaram, e estes eram "mais puros do que em qualquer outro núcleo nacional e, mesmo, do que entre os espanhóis fronteiriços" ${ }^{40}$ A pretensa superioridade social do gaúcho é inseparável do componente étnico, e Oliveira Viana nada fica a dever à máxima idealização literária do tipo local, ao fazer refletir, na fisiologia do gaúcho, qualidades morais:

Em suma, com a sua estatura elevada, o tórax amplo, o corpo espaduado e musculoso; tendo, na fisionomia franca, um ar de segurança; e a palavra sonora; e a imaginação hiperbólica; e os gestos desembaraçados; e mais a forte tendência para os exageros e as gabolices — tudo indica no gaúcho de outrora, como no gaúcho de hoje, o homem dotado de uma pletora de vida, um equilibrado, um forte, um eugênico, enfim. ${ }^{41}$

As consequências desta exaltação do gaúcho são de grande relevância, já que possibilitam ao autor identificar um comportamento político totalmente diverso do restante do país, e que corresponde exatamente àquelas virtudes cívicas que, na opinião do autor, só seriam desenvolvidas no Brasil a partir da formação de um estado centralizado capaz de estabelecer a autoridade, conferir uma diretriz segura à vida nacional e articular os interesses particulares em torno de um projeto comum. À tendência centrífuga das forças políticas do restante do país, identificada por Oliveira Viana, opóe-se automaticamente a consciência de coesão e de disciplina que o jurista identifica no Rio Grande do Sul. Verdadeiramente dotado de uma cultura regional, o estado seria caracterizado, portanto, por uma vocação para a vida pública ausente tanto no centro-sul quanto no Norte do país, instáveis, efêmeros, personalistas, mal dotados para a política por sua incapacidade de estabelecer, espontaneamente, um sentido de autoridade capaz de submeter os interesses individuais ao bem-estar coletivo.

\footnotetext{
${ }^{40}$ Ibidem, p. 330-331.

${ }^{41}$ Ibidem, p. 335. 
Portanto, na visão de Oliveira Viana, o "instinto de conservação" que moveu o desenvolvimento da sociedade rio-grandense e que conferiu a ela um original sentido de solidariedade implicou também o desenvolvimento de outra virtude ausente nas demais regiôes brasileiras: a consciência de que a ação individual deveria colar-se ao interesse público, tomando como base não a retórica e os sonhos, mas as providências concretas a serem tomadas para a reação a problemas reais e imediatos, ao contrário, portanto, do que seria o "idealismo utópico" das elites liberais do centro-sul. O conceito de "idealismo utópico" diz respeito, na obra de Oliveira Viana, à incapacidade das elites brasileiras de tomar consciência dos verdadeiros problemas nacionais, uma vez que se teriam deixado guiar por padróes exóticos, definidos a partir da observação de realidades sociais muito diferentes das brasileiras. Em contraponto, o "idealismo orgânico", segundo ele, "nasce da própria evolução orgânica da sociedade, sendo uma visão antecipada de uma evolução futura", conduzindo a um ordenamento social adequado às condiçóes materiais e espirituais de um povo. ${ }^{42}$ No caso brasileiro, o aparato político, jurídico e institucional do Estado teria sido criado a partir de uma compreensão falseada das necessidades nacionais, inspirada pela ideologia liberal, que seria adequada apenas a países que já possuiriam um nível adequado de organização, coesão e solidariedade. ${ }^{43}$

Ao contrário da evoluçáo histórica do restante do país, caracterizada por esforços desordenados e por uma integração social muito precária, o Rio Grande do Sul teria dado gênese a uma coletividade consciente das necessidades de defesa dos interesses comuns a todos os indivíduos. Fazendo uso do conceito criado pelo autor, poderíamos caracterizar a sociedade gaúcha, da forma como é descrita por Oliveira Viana, pelo que é definido como o "idealismo orgânico". Para Viana, da observância do princípio de autoridade poderia surgir, a partir do modelo do Rio Grande do Sul, uma sociedade organizada, coesa, submetida à legalidade das instituiçôes nacionais e livre, uma vez que o controle estatal garantiria o predomínio dos interesses coletivos sobre os individuais, impedindo que os poderosos impusessem suas vontades pelo uso da força. Isso responde à pergunta retórica que o autor se propóe ao final do livro: "Terá sido esta a razão daquele 'ar de liberdade' que Saint-Hilaire surpreendeu no aspecto dos homens dos pampas do sul, ao penetrar, pela primeira vez, nos começos do século passado, a imensidade daquelas planícies?”

Não há elementos para afirmar com segurança a que serve esta idealização romântica do tipo gaúcho por Oliveira Viana, muito embora seja tentador associar o elogio da autoridade,

\footnotetext{
${ }^{42}$ VIANNA, Oliveira. O idealismo da Constituição. 2. ed. São Paulo: Cia. Editora Nacional, 1939. p. 11.

${ }^{43}$ Como observou Stella Bresciani, aos métodos científicos, objetivos, positivos, era atribuída pelos críticos do liberalismo a capacidade de determinar os rumos próprios a serem seguidos pela sociedade brasileira em sua trajetória em direção à civilização, coerentemente com a índole nacional. Esses métodos científicos eram tidos como universais, independentemente de onde haviam sido criados, sendo, portanto, válidos para o desvendamento da realidade brasileira. O óbvio paradoxo é que, se por um lado está a crítica da cópia de modelos estrangeiros, por outro há o uso destes modelos para o conhecimento objetivo do país. BRESCIANI, Maria Stella Martins. O charme da ciência e a sedução da objetividade. Oliveira Vianna entre intérpretes do Brasil. São Paulo: Editora Unesp, 2005.
} 
da capacidade de liderança, do instinto solidário e da consciência do bem público ao processo político de centralização do poder iniciado no Brasil com a Revolução de 1930, com a ascensão do gaúcho Getúlio Vargas ao poder - anos mais tarde, Oliveira Viana tornava-se seu principal ideólogo. O fato é que, já no primeiro volume das Populaçôes Meridionais do Brasil, lançado em 1920, o jurista definia algumas das principais virtudes da sociedade gaúcha em oposição ao que seriam as deformações da ordem política do centro-sul. A identidade regional é descrita, repetidamente, a partir do contraste entre as condiçóes — sociais, políticas, geográficas, étnicas - superiores do estado em relação a uma alteridade interna (os demais grupos regionais brasileiros) e uma alteridade externa (os castelhanos). A função de defesa assumida historicamente no território da fronteira meridional, espaço simbólico de gestaçáo do tipo gaúcho, equivale, assim, a um destino a ser cumprido, tanto em nome da nacionalidade brasileira quanto de um ideal civilizador imposto à "desordem caudilhesca" dos países hispânicos.

Portanto, a afirmação da especificidade do Rio Grande do Sul no contexto brasileiro construiu uma longa tradição discursiva que se disseminou entre a literatura, a historiografia, os estudos sociais e, como vemos, a análise política. Dentre os elementos citados por Oliveira Viana em seu estudo, vários já haviam se consolidado como temas literários, conforme vimos: a harmonia entre o indivíduo e o meio físico, que comunicaria a ele o apreço pela liberdade; a invencibilidade heroica na guerra, dadas a força, a maleabilidade e agilidade da "cavalaria de centauros"; a lealdade do peáo-soldado aos chefes, como escola de obediência e de respeito absoluto à autoridade; a valorização do trabalho na estância, simultaneamente como diversão, formação para a guerra, ocupação cavalheiresca e prática democratizante, por promover o convívio cotidiano de peões e estancieiros; o reconhecimento coletivo ao mérito individual; o instinto patriótico que define suas lutas a partir da fidelidade à causa nacional; a virtude civilizadora frente à barbárie do inimigo platino; o vigor físico de uma etnia pretensamente estável, traduzido cientificamente como qualidade eugênica; a fixaçáo de uma cultura própria e fundamentalmente imutável; a aptidão para o exercício da autoridade e o poder de liderança em âmbito nacional. A partir da criação de uma mitologia enraizada na história do estado, os dados da realidade foram selecionados e significados em função de sua capacidade de mobilizaçáo política e de canalização dos conflitos internos e externos em direçấo a um consenso que, de forma algo dúbia, afirma a pertinência do Rio Grande do Sul à história brasileira, ao mesmo tempo que atribui ao estado uma missão nada corriqueira: não apenas sua brasilidade é inquestionável, como sua posição é sempre superlativa em face dos destinos nacionais. 


\section{Referências bibliográficas}

ACADEMIA BRASILEIRA DE LETRAS. Augusto Meyer. Biografia. Disponível em: <http://www.academia.org.br/academicos/augusto-meyer/biografia>. Acesso em: 21 jul. 2015.

ALENCAR, José de. O gaúcho. Porto Alegre: L\&PM, 2002 [1870].

. Prefácio. In: Sonhos d'ouro. São Paulo: Ática, 1981 [1872].

ALMEIDA, Marlene Medaglia. Na trilha de um andarengo. Alcides Maya (1877-1944). Porto Alegre: Mercado Aberto, Edipucrs, 2004.

ARINOS, Paulo [Moysés Vellinho]. O papel da nova geração. In: CHAVES, Flávio Loureiro (Org.). O ensaio literário no Rio Grande do Sul. (1868-1960). Rio de Janeiro: Livros Técnicos e Científicos; Brasília: INL, 1979.

BHABHA, Homi K. DissemiNação. O tempo, a narrativa e as margens da nação moderna. In: - O local da cultura. Tradução de Myriam Ávila, Eliana Lourenço de Lima Reis, Gláucia Renate Gonçalves. Belo Horizonte: Editora UFMG, 1998.

BRESCIANI, Maria Stella Martins. O charme da ciência e a sedução da objetividade. Oliveira Vianna entre intérpretes do Brasil. São Paulo: Editora Unesp, 2005.

CALLAGE, Roque. Índio × Caboclo. In: - Terra natal. Aspectos e impressóes do Rio Grande do Sul. Porto Alegre: Barcellos, Bertaso \& C., 1920.

- Lida nova. In: CALLAGE, Roque. Quero-quero. Scenas crioulas. Porto Alegre: Livraria do Globo, 1927.

CANDIDO, Antonio. O método crítico de Sílvio Romero. São Paulo: Edusp, 1988.

CARVALHO, José Murilo de. A utopia de Oliveira Viana. Estudos Históricos, Rio de Janeiro: Fundação Getulio Vargas, v. 4, n. 7, p. 83-99, 1991.

CÉSAR, Guilhermino. História da Literatura do Rio Grande do Sul (1737-1902). 3. ed. Porto Alegre: Instituto Estadual do Livro, Corag, 2006.

CHAVES, Flávio Loureiro. Simóes Lopes Neto. 2. ed. revista. Porto Alegre: Ed. da UFRGS, Instituto Estadual do Livro, 2001.

CUNHA, Euclides da. Os sertóes. Ed. crítica. São Paulo: Brasiliense, 1985 [1902].

FARIA, Luiz de Castro. Oliveira Vianna. De Saquarema à Alameda São Boaventura, 41 Niterói. O autor, os livros, a obra. Rio de Janeiro: Relume Dumará, 2002.

FOUCAULT, Michel. As palavras e as coisas. Uma arqueologia das ciências humanas. 8. ed. Tradução de Salma Tanus Muchail. São Paulo: Martins Fontes, 2000.

HOBSBAWM, Eric John Ernest. Naçóes e nacionalismo desde 1780. Programa, mito e realidade. 3. ed. Rio de Janeiro: Paz e Terra, 2002. 
LAZZARI, Alexandre. Entre a grande e a pequena pátria: letrados, identidade gaúcha e nacionalidade (1860-1910). Tese (doutorado) — Programa de Pós-graduação em História, Unicamp, Campinas, 2004.

LEITE, Lígia Chiappini Moraes. Regionalismo e modernismo. O caso gaúcho. São Paulo: Ática, 1978.

MACHADO, Propício da Silveira. Roque Callage: vida, obra e antologia. Porto Alegre: UFRGS, 1975.

MAYA, Alcides. Pelo futuro. Porto Alegre: Franco \& Irmão, 1897.

. O Rio Grande mental. In: MAYA, Alcides. Através da imprensa. Porto Alegre: Octaviano Borba \& Irmão, 1900.

. Ruinas vivas. 2. ed. Porto Alegre: Movimento; Santa Maria (RS): Editora UFSM, 2002.

MEYER, Augusto. Gaúcho, história de uma palavra. In: . Prosa dos pagos. 1941-1959. Rio de Janeiro: Livraria São José, 1960.

MURARI, Luciana. Brasil: ficção geográfica. Ciência e nacionalidade no país d'Os sertôes. São Paulo: Anablumme, Belo Horizonte: FAPEMIG, 2007.

- Messianismo e catástrofe. Algumas inflexôes políticas do debate raciológico brasileiro nas obras de Sílvio Romero, Nina Rodrigues e Oliveira Vianna. Agália, n. 1, v. 8, p. 103$128,2013$.

PORTO ALEGRE, Apolinário. O vaqueano: narrativa. Porto Alegre: Livraria do Globo, 1927 [1872].

SCHLANGER, Judith. Les métaphores de l'organisme. Paris: L'Harmattan, 1995.

SCHWARCZ, Lilia Moritz. O espetáculo das raças: cientistas, instituiçôes e questão racial no Brasil (1870-1930). São Paulo: Companhia das Letras, 1993.

VIANNA, Oliveira. Populaçôes meridionais do Brasil. Populaçôes rurais do centro-sul. 5. ed. Rio de Janeiro: José Olympio, 1952a [1920]. v. 1.

. Populaçóes meridionais do Brasil. O campeador rio-grandense. Rio de Janeiro: José Olympio, 1952b. v. 2.

. O idealismo da Constituição. 2. ed. São Paulo: Cia. Editora Nacional, 1939. 